$\begin{gathered}\text { EPiC Series in Education Science } \\ \text { Volume 1, 2017, Pages 187-195 }\end{gathered}$
$\begin{aligned} & \text { AUBEA 2017: Australasian Universities Build- } \\ & \text { ing Education Association Conference 2017 }\end{aligned}$

\title{
Inclusion and Wellbeing for People with Autism and the Role of Built Environment
}

\author{
Andrei Pomana ${ }^{1}$ \\ ${ }^{1}$ University of Newcastle, Newcastle, Australia \\ andrei.pomana@uon.edu.au
}

\begin{abstract}
Autism Spectrum Conditions are neurological disorders which make inclusion in society very difficult for the affected individuals. The main challenges that people with autism face are related to sensory processing disorders, communication difficulties and restricted repetitive patterns of behaviour. Current methods for integrating people with autism focus primarily on equipping autistic individuals with the tools to tolerate circumstances that they might find uncomfortable in social day-to-day situations. The society's response to accommodating the condition is usually restricted to improving access to selected spaces which often have limited functionality and give the autistic narrow margins for physical and intellectual development. The paper shows the preliminary results of a qualitative meta-analysis of the extant literature relating to societal aspects that need to be taken into account when considering the integration of people with autism. Also, employing the same methodology, the study explores the way in which built environment can have a contribution to the integration of people with autism and the degree to which inclusive physical space represents a positive factor to an autistic individual's subjective wellbeing and quality of life.
\end{abstract}

\section{Introduction}

The act of integrating non-typical individuals into the current structure of society involves both internal measures to alleviate the impact of disability and external circumstances that help people interact with the outside world. The later can only be achieved through two means: the adaptation of human behaviour to accommodate the needs of non-typical individuals and the adaptation of environments which favour the conditions of disabled people. Integration into society should not be the ultimate goal without establishing that achieving or increasing it has a beneficial effect on the wellbeing and quality of life (QoL) of people with disabilities. The aim of this paper is to determine the effect of an intervention to the built environment on people with autism from a wellbeing/QoL and integration point of view. As a result, wellbeing and integration become benchmarks for assessing the performance of such built environment intervention. The question that this study aims to answer is if, how and to 
what degree does built environment have the potential to increase wellbeing/QoL and integration of people with autism.

\section{Methodology}

The study presents the preliminary results of a meta-analysis on the current literature regarding the state of integration and wellbeing/QoL for people with disabilities and, in particular, people with autism. The number of studies included is limited by the preliminary form of this analysis and space constraints. The computer database Google Scholar was initially searched using different combinations of the keywords: autism, integration, disability, stigma, access, legislation, quality of life and wellbeing. Sources were also gathered through snowball sampling where suitable cited references from the initial sources were used. Papers discussing integration and wellbeing for people with autism were mainly focused on, however, when aspects overlapped, the investigation took a more general approach concentrating on all people with disabilities. The total number of 21 papers were classified into three categories in relation to the presented topic: integration and QoL/wellbeing of people with disabilities or autism. The date of publication did not represent a selection criteria, however, in the present text, focus was put on more recent publications. The study employs qualitative research methodologies to conduct an inquiry of the literature on the elements contributing to the integration of non-typical individuals. These aspects are separated into two categories: societal standards that are aiming towards the inclusion of non-typical individuals (integration enablers) and standards that restrict this process (integration barriers) - Table 1. Careful consideration is put on elements that facilitate or come against integration of people with autism and other cognitive disabilities where the disruptive nature of the disorder can cause different reactions from the public in comparison to other disabilities. For each aspect contributing to integration, an assessment on the influence of built environment is made as presenting a positive, negative or not applicable input towards inclusion.

Integration should be viewed as a means to an end and not an end in itself since individual outcome should possess more value to a person than current plans for an inclusive society. Therefore, the study analyses literature on wellbeing and $\mathrm{QoL}$ as different standards of human development for people with autism and assesses the capacity of integration to make an improvement on these benchmarks. QoL for people with autism is examined through several assessment tools. Built environment is analysed as having a positive, negative or not applicable input to the QoL of the autistic individual from four perspectives: psychological, physical, social and educational/work related - Table 2 . The potential of built environment to affect wellbeing for people with autism is analysed in the same way through three philosophical approaches: hedonistic, desire fulfilment and capabilitarian - Table 2.

\section{Integration of People with Autism}

In order to achieve significant integration results, autistic persons need to be prepared to cope with the present and near future expectations from society. However, integration should not be viewed from just one side. Not only is a civilized society's duty to take care of its members but not doing so will trigger immense social and economic burdens on family members and can have a detrimental effect on society at large. Society has developed two distinct ways to help people with disabilities integrate: alleviate or remedy a person's disability through scientific discoveries or reorganise the social and environmental structure in order to make accessible to the disabled as many experiences as possible. The barriers to integration in society for people with disabilities have multiple dimensions, but they mostly revolve around the lack of resources and society's perception of people with disabilities. 


\begin{tabular}{|c|c|c|c|}
\hline \multicolumn{4}{|c|}{ ntegration Barriers } \\
\hline Type & Description & $\begin{array}{l}\text { Role of } \\
\text { BE }\end{array}$ & Source \\
\hline $\begin{array}{l}\text { Income } \\
\text { Handicap }\end{array}$ & $\begin{array}{l}\text { Lower chances of employment and lower work } \\
\text { efficiency caused by disability }\end{array}$ & Positive & Sen 2004 \\
\hline $\begin{array}{l}\text { Conversion } \\
\text { Handicap }\end{array}$ & $\begin{array}{l}\text { Lower capacity to transform currency into } \\
\text { services due to a disability }\end{array}$ & Positive & Sen 2004 \\
\hline $\begin{array}{l}\text { Over } \\
\text { positive bias }\end{array}$ & $\begin{array}{l}\text { Viewing disabled individuals as more valuable or } \\
\text { capable }\end{array}$ & N/A & Crow 2000 \\
\hline Stigma & $\begin{array}{l}\text { Viewing disabled individuals as less capable or } \\
\text { valuable }\end{array}$ & N/A & $\begin{array}{l}\text { Barg et al 2010; } \\
\text { Trammell 2009 }\end{array}$ \\
\hline $\begin{array}{l}\text { Lack of } \\
\text { Access }\end{array}$ & $\begin{array}{l}\text { Restricted capacity to take part in activities due to } \\
\text { non-typical development }\end{array}$ & Positive & $\begin{array}{l}\text { Imrie and Kumar } \\
\text { 1998; Cahill and } \\
\text { Eggleston } 1995\end{array}$ \\
\hline Resources & $\begin{array}{l}\text { Limited time, financial and material support for } \\
\text { people with disabilities }\end{array}$ & Negative & $\begin{array}{l}\text { Knapp et al 2009; } \\
\text { Ganz } 2007\end{array}$ \\
\hline \multicolumn{4}{|c|}{ Integration Enablers } \\
\hline \multicolumn{4}{|c|}{ Non Discrimination } \\
\hline Legislation & $\begin{array}{l}\text { Insuring equal opportunities and treatment for } \\
\text { non-typical individuals }\end{array}$ & N/A & $\begin{array}{l}\text { Australian Human } \\
\text { Rights } \\
\text { Commission } 2012\end{array}$ \\
\hline $\begin{array}{l}\text { Shifting } \\
\text { social } \\
\text { attitudes }\end{array}$ & $\begin{array}{l}\text { Encouraging positive attitudes towards non- } \\
\text { typical individuals }\end{array}$ & N/A & $\begin{array}{l}\text { Daruwalla and } \\
\text { Darcy } 2005\end{array}$ \\
\hline Awareness & $\begin{array}{l}\text { Informing the public about non-typical } \\
\text { individuals in order to remove stigma and } \\
\text { encourage healthy interactions }\end{array}$ & N/A & $\begin{array}{l}\text { Dillenburger et al } \\
2013\end{array}$ \\
\hline \multicolumn{4}{|c|}{ Facilitation of people with disabilities to limit the impact of disability } \\
\hline $\begin{array}{l}\text { Financial } \\
\text { support }\end{array}$ & $\begin{array}{l}\text { Minimising the financial gap and conversion } \\
\text { between typical and non-typical individuals }\end{array}$ & N/A & $\begin{array}{l}\text { Ganz 2007; Greco } \\
\text { et al } 2005\end{array}$ \\
\hline Healthcare & $\begin{array}{l}\text { Insuring the access to medical help catered to } \\
\text { non-typical individuals }\end{array}$ & N/A & $\begin{array}{l}\text { Oswald and } \\
\text { Sonenklar } 2007\end{array}$ \\
\hline $\begin{array}{l}\text { Research } \\
\text { and medical } \\
\text { progress }\end{array}$ & $\begin{array}{l}\text { Advancing knowledge on the conditions of non- } \\
\text { typical individuals and discovering ways to } \\
\text { remedy disabilities }\end{array}$ & N/A & $\begin{array}{l}\text { Anagnostou et al } \\
2014\end{array}$ \\
\hline Education & $\begin{array}{l}\text { Improve teaching capacities for people with } \\
\text { disabilities }\end{array}$ & Positive & $\begin{array}{l}\text { Khare and } \\
\text { Mullick 2009; } \\
\text { Mostafa 2008 }\end{array}$ \\
\hline \multicolumn{4}{|c|}{ Guarantee of access to participation in every area of life } \\
\hline $\begin{array}{l}\text { Sensory } \\
\text { spaces }\end{array}$ & $\begin{array}{l}\text { Encourage the implementation of sensory } \\
\text { comfortable spaces for people with autism }\end{array}$ & Positive & $\begin{array}{l}\text { American } \\
\text { Psychiatric } \\
\text { Association 2013; } \\
\text { Mostafa 2008 }\end{array}$ \\
\hline $\begin{array}{l}\text { Identifiable } \\
\text { spaces }\end{array}$ & $\begin{array}{l}\text { Implementing markers that make spaces easily } \\
\text { identifiable }\end{array}$ & Positive & $\begin{array}{l}\text { Klinger and } \\
\text { Dawson } 2001\end{array}$ \\
\hline
\end{tabular}

Table 1: Barriers and Enablers for the Integration of People with Autism and the Role of Built Environment

Current societal structures are catered to and present the highest efficiency for typical individuals because they define the characteristics displayed in the largest number of people. Heavy costs are 
sustained by both private and public sector to support the care for people with disabilities (Snook and Webster, 1987), especially for a large number autistic individuals how require care their entire lives (Ganz, 2007; Knapp et al, 2009). The actions needed to remove social and educational barriers for people with autism can be regarded as measures that require low amounts of resources since they can be adjusted on a local level. Regarding built environment, however, the efforts become much larger because access needs to be insured for as many environments as possible in order to allow people to engage with activities and achieve optimal levels of personal and professional development. The problem becomes even more important when considering the amount of sensory feed-back we receive and rely on from our built environment and the sensory processing disorders that people with autism possess. However, once built environment is used in favour of disabled people it provides an essential tool for integration because it provides access and enables people to take advantage of the physical space without special care (Cahill and Eggleston, 1995; Imrie and Kumar, 1998).

Regarding financial gains, Amartya Sen (2004) argues that even if a person with disabilities earns similar incomes as a typical individual, he or she cannot convert that revenue into the same products and experiences because generally those services need to be catered to his or her particular needs, costing a lot more than it is commonly practiced (Sen, 2004, Nussbaum, 2006). He refers to this aspect as "conversion handicap" which is different from "income handicap" identified as the circumstance where people with disabilities find it harder to find and maintain jobs which will inevitably impact their earnings (Sen, 2004). When referring to people with autism, the "conversion handicap" can manifest in different ways and can have a highly variable impact due to the large dissimilarities between autistic individuals.

In her writings, Jones (2011) points out that there are three dimensions of inclusion that must be fulfilled in order for people with disabilities to be incorporated in society: "a non-discriminatory attitude towards people with disabilities; the guarantee of access to participation in every area of life; and the facilitation of people with disabilities to limit the impact of disability" (Jones, 2011). To a large degree, western societies have had good results in establishing a non-discriminatory attitude towards people with disabilities. Regulations have been put in place to disrupt discrimination and encourage integration for disabled individuals (Australian Human Rights Commission, 2012). The awareness brought by information about people with disabilities translate into useful tools that typical individuals use to accommodate non-typical individuals (Dillenburger et al, 2013) as well as in a shift in attitudes which transform disabled people from tolerated members into contributing members of the society (Daruwalla and Darcy, 2005). However, even in the world's most progressive societies, a barrier to integration is bias against people with disabilities. This can be achieved both through self-stigmatization or from stigmatization by the general public. Studies show that people with autism and their caregivers face more severe stigma due to disruptive behaviours caused by autism (Trammell, 2009; Barg et al, 2010). On the other hand, people with disabilities can be viewed as outsiders through positive biases or biases of low expectations (Crow, 2000). Because the costs of living with a disability are higher in almost all aspects of life in comparison to typical individuals, society needs to provide people with disabilities with the financial support that will allow them to develop to their full potential (Greco et al, 2005; Oswald and Sonenklar, 2007).

The end goal should be the complete remedy of disabilities or alleviation of the symptoms through research (Anagnostou et al, 2014), because it would provide people the access to experience things outside the concrete structures that humans have developed over time. Integration into society also means having the skills to approach activities that typical individuals can easily acquire. For this to happen, different education methods need to be explored and established in order to cater to the needs of non-typical individuals (Khare and Mullick, 2009).

The guarantee of access to participation in every area of life takes inclusion a step forward from the non-discriminatory attitude towards people with disabilities and transforms them from tolerable members into participatory members of the society. The inclusion of people with disabilities in all areas of life has two layers: the physical implementation of environments that would limit the impact of 
disability and training typical individuals in understanding the disabilities and challenges that people with disability face. The second aspect is particularly important for people with cognitive disorders where typical individuals are a lot less likely to identify and make proper judgments on how to approach and interact with people with disabilities. Because autistic individuals possess sensory processing disorders (Mostafa, 2008; American Psychiatric Association, 2013) as well as deficiencies in prototype formation and generalization issues (Klinger and Dawson, 2001), the built environment has a much larger influence on their potential to navigate and interact in present day to day circumstances.

\section{Outcome of People with Autism - Wellbeing and QoL}

QoL and wellbeing are both benchmarks for the condition of an individual in regard to their social, economic, physical, psychological and spiritual state. However, the difference between these two terms refers to the point of view from which the characteristics are seen. Wellbeing represents an individual's condition in relation to his own ideals, whereas QoL relates to a person's standards and to society's norm of what a perfect outcome would look like.

\begin{tabular}{|l|l|l|l|}
\hline Quality of Life & Description & $\begin{array}{l}\text { Role of } \\
\text { BE }\end{array}$ & Source \\
\hline Type & Levels of bodily health, comfort, autonomy & N/A & van Heijst 2013 \\
\hline Physical & Capacity for interpersonal activities & Positive & van Heijst 2013 \\
\hline Social & $\begin{array}{l}\text { Potential to pursue, acquire and engage in } \\
\text { activities that require skill development }\end{array}$ & Positive & van Heijst 2013 \\
\hline $\begin{array}{l}\text { Education/ } \\
\text { work }\end{array}$ & $\begin{array}{l}\text { Ability to feel safe, engage and experience } \\
\text { feelings, thoughts and beliefs }\end{array}$ & Positive & van Heijst 2013 \\
\hline Psychological & Presence of pleasure and absence of pain & Positive & Parfit 1984 \\
\hline Wellbeing & $\begin{array}{l}|l| \\
\text { Pleasure } \\
\text { fulfilment }\end{array}$ & Positive & Parfit 1984 \\
\hline $\begin{array}{l}\text { Desire } \\
\text { fulfilment }\end{array}$ & Capacity to engage in activities that one might & Positive & $\begin{array}{l}\text { Sen 2004; } \\
\text { Robeyns, 2016; } \\
\text { Parfit 1984 }\end{array}$ \\
\hline Capabilitarian & find valuable & & \\
\hline
\end{tabular}

Table 2: Quality of Life and Wellbeing of People with Autism and the Role of Built Environment

Establishing the QoL for people with autism can be done through proxy reported or self-reported questionnaires. Research reveals that in many cases, people with autism can assess their QoL in a valid and reliable manner, even during their childhood (Shipman et al, 2011). Similar to typical developing individuals, children with autism report better QoL in comparison to their proxy reported QoL assessment. The difference comes especially when considering the non-observable aspects such as emotional, spiritual and social elements which tend to be estimated from higher standards by the caregivers of younger people (van Heijst, 2013). Also, because of their social and communication disorders, there can be expected even higher discrepancy levels between self-reported and proxy reported QoL. However, in almost all circumstances, people with autism have been found to show lower levels of QoL in comparison to people without autism in a few key areas such as relationships, leisure and social activities (van Heijst, 2013). The influence of built environment in increasing QoL for people with autism is hard to determine. However, the evidence suggests that comfortable surroundings lower the sensory burden (Mostafa, 2008) which would facilitate the accessibility to social spaces. Also, it is 
reasonable to assume that if lower sensory stimulus determines an increase in learning performance, it would also provide better surroundings for social interaction.

Considering the QoL assessment tools available, the question still remains to whether inclusion in all levels of society would increase the QoL scores for people with autism. As inclusion implies a high likelihood of social interaction, it is easy to assume that integration in all levels of society would determine higher opportunities to engage in meaningful relationships with peers. Also, having a nondiscriminatory approach and insuring access will determine a rise in the number of leisure activities in which people with autism can get involved in order to enrich the experiences they have in their social relationships. By providing autistic people with tools that limit the impact of their condition, they will have more resources and higher capacities to pursue the activities that they value. Therefore, inclusion can be used as a reliable instrument for improving the QoL for autistic individuals. Also, it represents a safe approach since it does not force them into actions that people in general consider to boost wellbeing, but rather offers them more opportunities to engage with activities and people that they value.

In terms of what society more rigidly considers to represent a good individual outcome and QoL, studies show that there are three factors that would considerably add to the success of a person with autism: early language development, a higher intelligence coefficient, above 70 (Howlin et al, 2004; van Heijst, 2013) and less severe autistic symptoms (Eaves and Ho, 2008; Kuhlthau et al, 2010). These three aspects should not be considered separately, but rather as a matrix where each one is dependent on the other. Studies show that language development has a strong influence on autistic people's cognitive progress especially in the early years (Mawhood et al, 2000). Having less severe autism symptoms would allow the autistic child to engage in more diverse activities for a longer period of time which would boost his information intake and improve his cognitive abilities (Mostafa, 2008). Therefore, achieving a better outcome would definitely be influenced by lowering the impact of autism symptoms by addressing the sensory processing disorders which in turn will have a beneficial influence on language development and cognitive abilities.

Wellbeing is a more complex issue to analyse when considering the fact that it is a subjective measure, different from person to person and almost impossible to clearly establish with reliable tools. As a result, determining whether inclusion is society through built environment would have a beneficial effect for people with autism can become a difficult task.

The hedonistic theory of wellbeing considers that fulfilment and happiness comes from the simple presence of pleasure and absence of pain (Parfit, 1984). Although at a first glance these aspects seem to hold true for most of people's perceptions, the theory comes to scrutiny when it is recognized that many feelings that people hold valuable and necessary come as painful experiences, such as longing or wishful thinking. The same can be said about the desire fulfilment theory where it is impossible to establish a general trend of achievements that all people value (Parfit, 1984). The objective list theory of wellbeing is not without its flaws, but it is probably the most appropriate approach when considering the fulfilment and happiness of people with disabilities. It focuses on the assumption that certain functionings, that people have reason to value, must be insured in order for them to be able to have the necessary tools to achieve wellbeing (Parfit, 1984; Robeyns, 2016). Because it refers to a list of aspects that humans have reason to value, the objective list approach provides a far more reliable benchmark for assessing people's wellbeing since it is judged within the same parameters. However, for this to become a subjective measure, unlike QoL criteria, the focus must mainly be put on the capability of a person to do something, rather than the achievement itself. This also gives people the option to decide for themselves how their lives should look like with no rigid limiting factors from society. 


\section{Conclusion}

Because it can provide people with autism with comfortable circumstances to conduct social, leisure and intellectual activities, built environment has a great potential to become an important tool in increasing the outcome of people with autism. Evidence shows that built environment has a larger impact on QoL/wellbeing than on integration because it can specifically address the individual's needs, rather than the requirements of a larger group. Also, in terms of wellbeing/QoL for people with autism, built environment becomes an essential tool due to the enormous beneficial impact that a comfortable sensory environment can provide. The physical QoL of people with autism is the least impacted by built environment since it may facilitate, but cannot fully address the bodily functions and internal physical comfort of an individual. Regarding psychological, social and educational/work related QoL, appropriate built environment has a much larger beneficial impact due to its capacity to produce less stress and increase focus on tasks or social/leisure activities. Social and educational/work related QoL are positively influenced by psychological QoL which provides autistic individuals with the necessary state of mind to conduct activities.

An appropriate built environment can have a beneficial effect on the wellbeing of people with autism especially considering the hedonistic approach where painful experiences caused by uncomfortable surroundings are seen as undesirable. In regard to the other two philosophical approaches to wellbeing, built environment can have a beneficial effect because it can offer people with autism the pathway to take advantage of the activities that are made available to them.

In regard to inclusion in society, built environment cannot determine successful results due to the many aspects that need to be met in order for integration to happen. However, because it is the main variable for insuring accessibility, built environment is essential when considering integration for people with autism, due to the sensory and generalization issues that are prevalent in autism. The biggest impact that built environment has on the integration of people with autism relates to its ability to provide access and suitable surroundings for individuals to engage in actions that benefit their development, such as education, work, social and leisure activities. As a result, the environment determines an indirect beneficial impact on autistic people's ability to gain skills and resources, which allow them to pursue their personal goals. The largest barrier to integration is the limited amount of resources that can be allocated for transforming built environment into a comfortable living ground for people with disabilities. The lack of labour participation represents one of the biggest costs that society pays for a non-inclusive environment. However, because the requirements of people with disabilities are so diverse and demand extensive modifications to the current structure, society is in a continuous struggle for resources that advance inclusivity, but still offer a fair benefit for typical individuals.

\section{References}

American Psychiatric Association (2013). DSM 5: American Psychiatric Association Anagnostou, E., Zwaigenbaum, L., Szatmari, P., Fombonne, E., Fernandez, B. A., WoodburySmith, M., ... \& Buchanan, J. A. (2014). Autism spectrum disorder: advances in evidence-based practice. Canadian Medical Association Journal, 186(7), 509-519.

Australian Human Rights Commission (2012) - Know your rights: Disability discrimination

Barg, C. J., Armstrong, B. D., Hetz, S. P., \& Latimer, A. E. (2010). Physical disability, stigma, and physical activity in children. International Journal of Disability, Development and Education, 57(4), 371-382.

Ben-Sasson, A., Hen, L., Fluss, R., Cermak, S. A., Engel-Yeger, B., \& Gal, E. (2009). A metaanalysis of sensory modulation symptoms in individuals with autism spectrum disorders. Journal of autism and developmental disorders, 39(1), 1-11 
Cahill, S. E., \& Eggleston, R. (1995). Reconsidering the stigma of physical disability. The Sociological Quarterly, 36(4), 681-698.

Cottenceau, H., Roux, S., Blanc, R., Lenoir, P., Bonnet-Brilhault, F., \& Barthélémy, C. (2012). Quality of life of adolescents with autism spectrum disorders: comparison to adolescents with diabetes. European child \& adolescent psychiatry, 21(5), 289-296 859).

Crow, L. (2000). Helen Keller: Rethinking the problematic icon. Disability \& Society, 15(6), 845-

Daruwalla, P., \& Darcy, S. (2005). Personal and societal attitudes to disability. Annals of Tourism Research, 32(3), 549-570

Dillenburger, K., Jordan, J. A., McKerr, L., Devine, P., \& Keenan, M. (2013). Awareness and knowledge of autism and autism interventions: A general population survey. Research in Autism Spectrum Disorders, 7(12), 1558-1567.

Eaves, L. C., \& Ho, H. H. (2008). Young adult outcome of autism spectrum disorders. Journal of autism and developmental disorders, 38(4), 739-747.

Ganz, M. L. (2007). The lifetime distribution of the incremental societal costs of autism. Archives of pediatrics \& adolescent medicine, 161(4), 343-349.

Greco, V., Sloper, P., Webb, R., \& Beecham, J. (2005). An exploration of different models of multiagency partnerships in key worker services for disabled children: effectiveness and costs. Social Policy Research Unit, University of York.

Howlin, P., Goode, S., Hutton, J., \& Rutter, M. (2004). Adult outcome for children with autism. Journal of Child Psychology and Psychiatry, 45(2), 212-229.

Imrie, R., \& Kumar, M. (1998). Focusing on disability and access in the built environment. Disability \& Society, 13(3), 357-374

Jones, M. (2011). Inclusion, social inclusion and participation. In Critical Perspectives on Human Rights and Disability Law (pp. 57-82). Brill.

Khare, R., \& Mullick, A. (2009). Incorporating the behavioral dimension in designing inclusive learning environment for autism. Archnet-ijar, 3(3).

Klinger, L. G., \& Dawson, G. (2001). Prototype formation in autism. Development and Psychopathology, 13(01), 111-124.

Knapp, M., Romeo, R., \& Beecham, J. (2009). Economic cost of autism in the UK. Autism, 13(3), 317-336.

Kuhlthau, K., Orlich, F., Hall, T. A., Sikora, D., Kovacs, E. A., Delahaye, J., \& Clemons, T. E. (2010). Health-related Quality of life in children with autism spectrum disorders: Results from the autism treatment network. Journal of autism and developmental disorders, 40(6), 721-729.

Mawhood, L., Howlin, P., \& Rutter, M. (2000). Autism and developmental receptive language disorder-A comparative follow - up in early adult life. I: Cognitive and language outcomes. Journal of Child Psychology and Psychiatry, 41(5), 547-559.

Mostafa, M. (2008). An architecture for autism: Concepts of design intervention for the autistic user. Archnet-IJAR: International Journal of Architectural Research, 2(1), 189-211.

Nussbaum, M. (2006) Frontiers of justice. Harvard University Press

Oswald, D. P., \& Sonenklar, N. A. (2007). Medication use among children with autism spectrum disorders. Journal of child and adolescent psychopharmacology, 17(3), 348-355.

Parfit, D. (1984). Reasons and persons. OUP Oxford.

Robeyns, I. (2016). Conceptualising well-being for autistic persons. Journal of medical ethics, 42(6), 383-390.

Sen, A. (2004, November). Disability and justice. In Disability and Inclusive Development Conference, keynote speech, World Bank. Washington, DC. Processed 
Shipman, D. L., Sheldrick, R. C., Perrin, E. C. (2011). Quality of life in adolescents with autism spectrum disorders: Reliability and validity of self-reports. Journal of Developmental and Behavioral Pediatrics, 32, 85-89

Snook, S. H., \& Webster, B. S. (1987). The cost of disability. Clinical orthopaedics and related research, 221, 77-84.

Trammell, J. (2009). Postsecondary students and disability stigma: Development of the postsecondary student survey of disability-related stigma (PSSDS). Journal of Postsecondary Education and Disability, 22(2), 106-116.

van Heijst, B. F. (2013). Quality of life in autism across the lifespans 